Jurnal IImu Komputer dan Informatika Vol 2 № 2

p-ISSN: $2776-7418$ e-ISSN: 2746-508X

\title{
PERANCANGAN FIREWALL FILTERING DAN MANAJEMEN BANDWIDTH MENGGUNAKAN ROUTER MIKROTIK PADA JARINGAN KOMPUTER SMA NEGERI 1 SEPUTIH BANYAK LAMPUNG TENGAH
}

\author{
Dika Apriyanto 1), Sudarmaji ${ }^{2)}$, Arif Hidayat ${ }^{3)}$ \\ ${ }^{\left.1-3^{*}\right)}$ Program Studi IImu Komputer, Fakultas IImu Komputer \\ Universitas Muhammadiyah Metro \\ Jl. Gatot Subroto, Yosodadi, Metro Timur, Kota Metro
}

\begin{abstract}
Abstrak : Tujuan dari penelitian ini adalah memberikan perancangan firewall filtering dan manajemen bandwidth menggunakan MikroTik Router, memperluas ruang lingkup jaringan di SMA Negeri 1 Seputih Banyak, Dalam penyusunannya penulis menggunakan metode R\&D (Research and Development). Hasil dari penelitian ini berupa pengembangan sistem jaringan pada SMA Negeri 1 Seputih Banyak. Diantaranya, memperluas ruang lingkup untuk akses jaringan internet di lingkungan SMA Negeri 1 Seputih Banyak serta dibuatkan nya konfigurasi manajemen bandwidth dan firewall filtering untuk para siswa/siswi SMA Negeri 1 Seputih Banyak.
\end{abstract}

Kata Kunci: firewall filtering, manajemen bandwidth, mikrotik router,siswa/siswi

Abstract : The Purpose of this research is to give a firewall filtering design and bandwidth management using MikroTik Router, to expand the scope of the network at SMA Negeri 1 Seputih Banyak. This research using R\&D method (research and development). The result of this research is a network system development at SMA Negeri 1 Seputih Banyak. Such as, expand scope for the internet network access at SMA Negeri 1 Seputih Banyak environment then it made bandwidth management configuration and firewall filtering for the students of SMA Negeri 1 Seputih Banyak.

Keywords: firewall filtering, bandwidth management, mikrotik router, the students

\section{PENDAHULUAN}

Produk yang dikembangkan oleh penulis adalah sistem jaringan yang berada di SMA Negeri 1 Seputih Banyak dimana belum adanya user ID untuk para siswa/siswi dan ruang lingkup akses jaringan yang masih masih terbatas. Pengembangan sistem jaringan ini memungkinkan agar siswa/siswi dapat mengakses jaringan internet dan memperluas ruang lingkup akses jaringan dapat mempermudah user dalam mengakses jaringan di lingkungan SMA Negeri 1 Seputih
Banyak. Tujuan dari penelitian ini menghasilkan produk berupa sistem konfigurasi jaringan yaitu filtering dan manajemen bandwidth menggunakan MikroTik Router OS V 5.20 dan memperluas ruang lingkup jaringan agar guru, staf TU, waka, kepala sekolah dan siswa/siswi bisa mengakses jaringan internet dengan mudah di lingkungan SMA Negeri 1 Seputih Banyak.

Jenis penelitian yang digunakan adalah penelitian pengembangan atau Research and Development (R\&D). 
Model yang digunakan peneliti adalah model 4D (Define, Design, Development, and Disseminate) yang dikembangkan oleh Thiagarajan. Model ini terdiri dari 4 tahapan yaitu define (menganalisis kebutuhan), design (merancang suatu produk), development (mengembangkan produk yang didesain), dan terakhir disseminate (penyebaran produk). Setelah melakukan kegiatan penelitian di SMA Negeri 1 Seputih Banyak, maka penulis dapat menyimpulkan bahwa kondisi sistem jaringan yang saat ini berjalan sudah cukup baik, namun masih ada beberapa kekurangan yaitu sebagai berikut, kurangnya ruang lingkup akses jaringan internet di SMA Negeri 1 Seputih Banyak sehingga jaringan internet hanya dapat diakses di area tertentu saja, belum adanya konfigurasi sistem jaringan untuk siswa/siswi SMA Negeri 1 Seputih Banyak sehingga para siswa/siswi ini hanya dapat mengakses jaringan internet di area LAB komputer saja. Oleh karena itu, penulis melakukan penelitian ini guna untuk mengembangkan sistem jaringan yang ada pada SMA Negeri 1 Seputih Banyak, berdasarkan perancangan sistem jaringan yang dibangun pada SMA Negeri 1 Seputih Banyak adalah sebagai berikut, memperluas ruang lingkup akses jaringan internet di SMA Negeri 1 Seputih Banyak sehingga guru, staf TU, waka, dan kepala sekolah dapat mengakses jaringan internet dengan mudah di lingkungan SMA Negeri 1 Seputih Banyak, dibuatkannya konfigurasi sistem jaringan untuk para siswa/siswi SMA Negeri 1 Seputih Banyak sehingga para siswa/siswi juga dapat mengakses jaringan internet dengan mudah.

\section{KAJIAN PUSTAKA DAN}

Jurnal IImu Komputer dan Informatika Vol 2 № 2 p-ISSN: $2776-7418$ e-ISSN: 2746-508X Jaringan Komputer

Syafrizal (2015: 2) menyimpulkan "Jaringan komputer adalah himpunan" interkoneksi" antara 2 komputer autonomous atau lebih yang terhubung dengan media transmisi kabel atau tanpa kabel (wireless)". Sedangkan menurut MADCOMS (2016: 11-12) menjelaskan "Sistem jaringan komputer merupakan sebuah sistem yang terdiri atas komputer dan perangkat jaringan lainnya yang bekerja sama untuk mencapai suatu tujuan yang sama".

\section{Mikrotik Router}

MADCOMS (2016: 1) menarik kesimpulan sebagai berikut "MikroTik Router merupakan salah satu produk dari MikroTik yang berupa perangkat lunak. Router berfungsi sebagai sistem operasi yang di install pada PC (Personal Computer). Sistem operasi ini akan mengubah computer tersebut menjadi sebuah router dengan segala fitur yang sudah ada di dalamnya". Namun menurut Wanda (2020: 59) menarik kesimpulan sebagai berikut "MikroTik adalah sistem operasi dan perangkat lunak yang dapat digunakan untuk menjadikan komputer menjadi router network yang handal, mencakup berbagai fitur yang dibuat untuk IP network dan jaringan wireless, cocok digunakan oleh ISP, provider hotspot dan warnet".

\section{Firewall Filtering}

Pribadi (2008: 45) menyimpulkan "firewall yang dimaksud di sini adalah mekanisme perlindungan sebuah mesin atau sistem dari ancaman yang merugikan jaringan internet atau jaringan komputer". Namun menurut MADCOMS (2016: 165) menyimpulkan "firewall 
berfungsi menjaga keamanan jaringan dari ancaman pihak lain yang tidak berwenang. Mengubah, merusak atau menyebarkan datadata tidak penting suatu perusahaan merupakan contoh ancaman yang patut dicegah".

\section{Manajemen Bandwidth}

MADCOMS (2016:

menyimpulkan "prinsipnya, bandwidth tiap client akan dibatasi penggunaanya. Bandwidth yang tidak dibagi secara merata menyebabkan koneksi di beberapa tipe client yang tidak sama antara satu dengan lainnya". Namun menurut Ilham (2020: 179) menarik kesimpulan sebagai berikut "Tujuan pengolahan bandwidth ini adalah agar client mendapatkan bandwidth yang merata sesuai dengan yang dialokasikan. Manajemen bandwidth dikenal dengan istilah Quality of Service (QoS) yaitu Teknik yang digunakan untuk menjamin setiap client mendapat alokasi bandwidth masing-masing sehingga proses pertukaran data pada jaringan bisa berjalan optimal".

\section{METODE}

Dalam penelitian ini, penulis menggunakan metode Research and Development biasa disingkat menjadi $R \& D$, merupakan metode penelitian yang digunakan untuk menghasilkan produk tertentu, dan menguji keefektifan produk tersebut.

\section{Setting Bridge Pada VirtualBox} Melakukan setting bridge pada VirtualBox diperlukan karena untuk

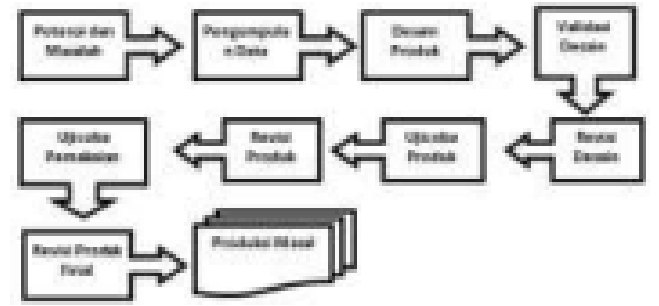

Gambar 1. Metode Research and Development.

Dalam melaksanakan penelitian ini penulis menggunakan teknik pengumpulan data studi lapang yang terdiri beberapa tahapan sebagai yaitu wawancara, dokumentasi, observasi, studi pustaka. Penulis melaksanakan kegiatan penelitian ini di SMA Negeri 1 Seputih Banyak tepat pada tanggal 2 Desember 2020.

\section{HASIL DAN PEMBAHASAN Topologi Jaringan}

Langkah awal dalam melakukan perancangan sistem jaringan untuk SMA Negeri 1 Seputih Banyak diperlukan gambaran topologi jaringan, topologi yang akan digunakan adalah topologi star, gambaran topologi yang hendak digunakan sebagai yaitu berikut:

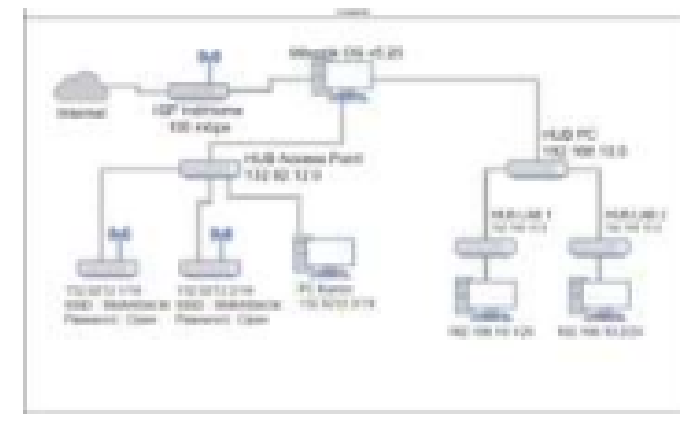

Gambar 1. Metode Research and Development.

menentukan berapa port yang hendak digunakan dan juga menentukan peran dari setiap port nya. 


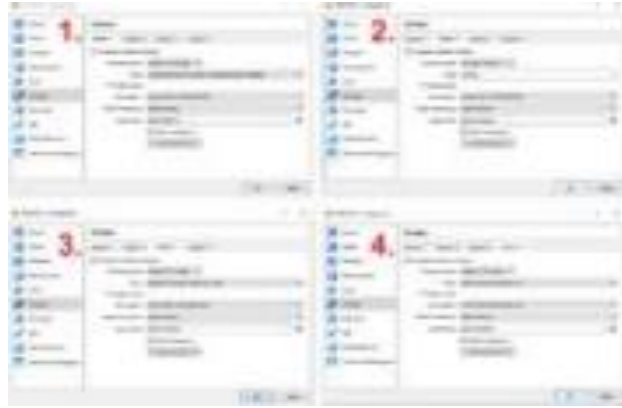

Gambar 3. Setting bridge VirtualBox.

\section{Install MikroTik}

Berikut merupakan instalasi machine MikroTik OS di VirtualBox yang akan digunakan sebagai router jaringan untuk memanajemen bandwidth dan firewall filtering sistem jaringan di SMA Negeri 1 Seputih Banyak.

\section{Konfigurasi Hotspot}

Berikut merupakan konfigurasi hotspot setting menggunakan MikroTik router. Output dari hotspot setting berupa jaringan wireless agar perangkat HP atau laptop user dapat terkoneksi, langkah-langkah setting hotspot dapat dilihat pada Gambar 5.

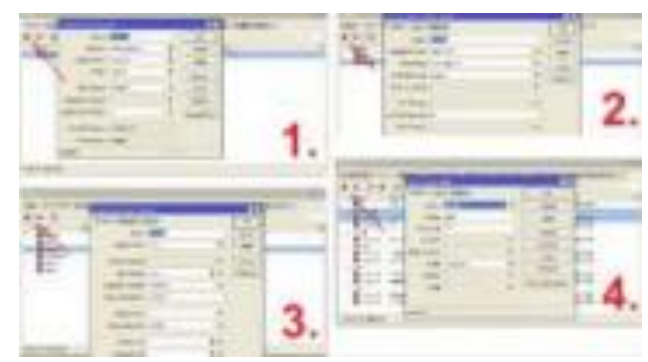

Gambar 5. Konfigurasi Hotspot.

\section{Fitur Firewall Filtering}

Fitur firewall filtering bertujuan untuk membatasi hak akses user dalam penggunaan jaringan internet, contoh penerapan nya jika user hendak mengakses situs yang tidak perlu atau mengakses game online pada waktu yang telah ditentukan maka user tersebut tidak dapat mengakses situs atau game online tersebut yang telah filtering oleh MikroTik, berikut adalah contoh penerapan nya.

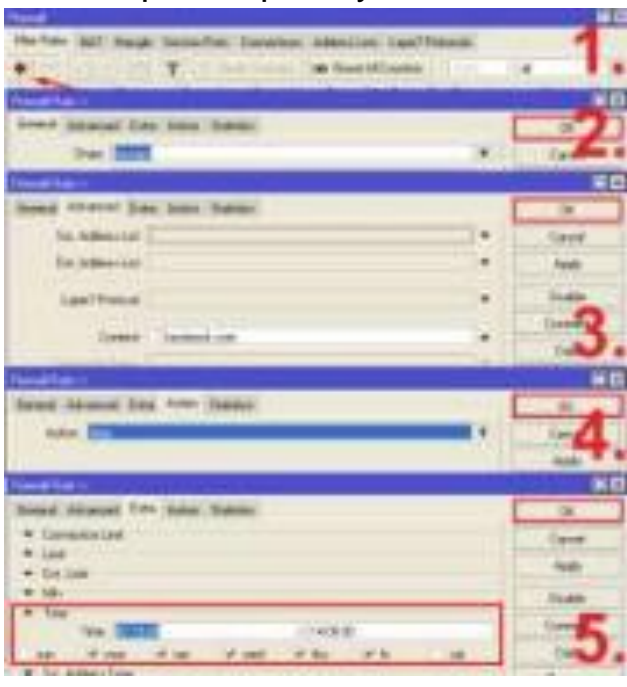

Gambar 6. Fitur firewall filtering.

\section{User Manajemen Bandwidth}

Manajemen bandwidth berfungsi untuk mengatur bandwidth dari setiap user yang ada malai dari user jaringan lokal atau LAN dan jaringan hotspot agar penggunaan jaringan menjadi lebih baik, cepat, efektif dan efisien.

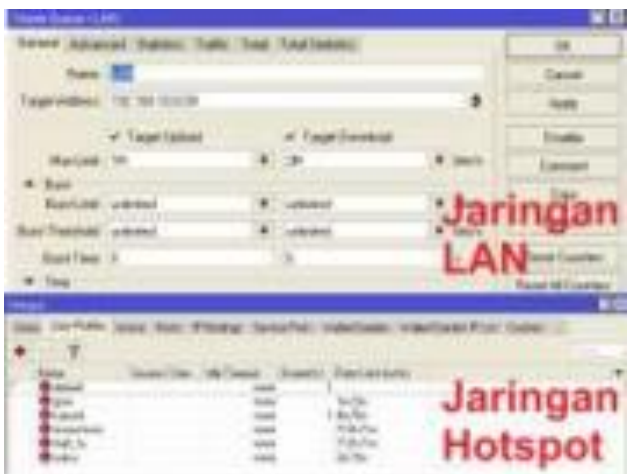

Gambar 7. User manajemen bandwidth.

\section{Testing Jaringan}

Dari konfigurasi yang telah dilakukan berikut merupakan testing jaringan yang terdiri dari jaringan LAN, hotspot, manajemen bandwidth, dan firewall filtering, hasil dari testing jaringan dapat dilihat pada Gambar 8. 

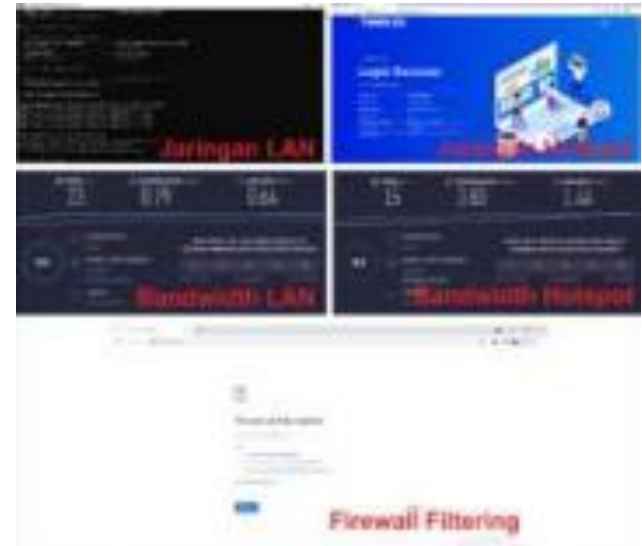

\section{KESIMPULAN}

Setelah kegiatan penelitian di SMA Negeri 1 Seputih Banyak telah peneliti lakukan, maka dari hasil yang diperoleh penulis dapat menyimpulkan kondisi sistem jaringan yang saat ini berjalan sudah cukup baik, namun masih terdapat beberapa kekurangan sebagai berikut:

a. Kurangnya ruang lingkup akses jaringan internet di SMA Negeri 1 Seputih

b. Banyak sehingga jaringan internet hanya dapat diakses di area tertentu saja.

c. Belum adanya konfigurasi sistem jaringan untuk siswa/siswi SMA Negeri 1 Seputih Banyak sehingga para siswa/siswi ini hanya dapat mengakses jaringan internet di area LAB komputer saja.

Oleh sebab itu, tujuan dari penulis melakukan penelitian ini adalah untuk mengembangkan sistem jaringan yang ada pada SMA Negeri 1 Seputih Banyak, berdasarkan perancangan sistem jaringan yang dibangun di sekolah tersebut adalah sebagai berikut:

a. Memperluas akses jaringan internet yang berada di sekolah tersebut sehingga guru, staf TU, waka, dan kepala sekolah dapat mengakses jaringan internet dengan mudah di lingkungan SMA Negeri 1 Seputih Banyak.

b. Dibuatkan konfigurasi sistem jaringan untuk pada siswa/siswi SMA Negeri 1 Seputih Banyak sehingga para siswa/siswi juga dapat mengakses jaringan internet dengan mudah.

c. Dengan adanya sistem yang dibangun ini dapat mempermudah dalam kegiatan mengajar siswa/siswi, dan juga dapat membantu dalam kegiatan yang membutuhkan jaringan internet.

d. Pada sistem jaringan yang dibangun juga terdapat fitur manajemen bandwidth yang digunakan user sehingga penggunaan jaringan internet dapat terkontrol dan diatur sesuai kebutuhan, dan terdapat fitur firewall filtering yang dapat digunakan dalam membatasi hak akses user dalam menggunakan jaringan internet.

e. Pada PC kantor menggunakan IP binding yang bertujuan untuk client PC kantor mendapatkan IP yang tetap dan tanpa harus melakukan login hotspot berulang kali. 


\section{DAFTAR PUSTAKA}

[1] Haryanto, V, E. 2012. Jaringan Komputer. Edisi Pertama. CV ANDI OFFSET. Yogyakarta.

[2] Ilahi, I., 2020. Administrasi Infrastruktur Jaringan. Edisi Pertama. XP Solution. Surabaya.

[3] Mardiyana, O, K, G, I. 2015. Keamanan Jaringan Dengan Firewall Filter Berbasis Mikrotik Pada Laboratorium Komputer STIKOM Bali, h. 804-807.

[4] MADCOMS. 2016. Manajemen Sistem Jaringan Komputer Dengan Mikrotik RouterOS. Edisi Pertama. Andi. Yogyakarta.

[5] Nurfauzi, A., Nainggolan, E, R., Khasanah, N, S., dan Setiadi, A. 2018. Implementasi Firewall Filtering Web dan Manajemen Bandwidth Menggunakan Mikrotik, 1(1), h.162167.

[6] Oktafiano, A, D. 2019. Riset Pendidikan Geografi. Cetakan Pertama. Cv. Cipta Griya Pustaka. Kalimantan Selatan.

[7] Pribadi, H., 2008. Firewall Melindungi Jaringan Dari DDoS Menggunakan Linux dan Mikrotik. Cetakan Pertama. Andi. Yogyakarta.

[8] Primabhaktik, R, P. 2018. PERANCANGAN PENGEMBANGAN JARINGAN KOMPUTER UNTUK LAYANAN PEMBELAJARAN DI SMPN 1 CIMANGGUNG. Skripsi tidak diterbitkan. Bandung: Fakultas Teknik Universitas Pasundan Bandung.
[9] Rafiudin, R. 2003. Mengupas Tuntas Cisco Router. Cetakan Kedua. PT Elex Media Komputindo Kelompok Gramedia. Jakarta.

[10] Salim dan hadir. 2019. Penelitian Pendidikan Metode, Pendekatan, dan Jenis. Cetakan Pertama. Kencana. Jakarta.

[11] Sujalwo, Handaga, B., dan Supriyono, $\mathrm{H}$. MANAJEMEN JARINGAN KOMPUTER DENGAN MENGGUNAKAN MIKROTIK ROUTER (COMPUTER NETWORK MANAGEMENT USED WITH MIKROTIK ROUTER), 2(2), h. 32-43.

[12] Sukaridhoto, S. 2014.Buku Jaringan Komputer I. Edisi Pertama. Politeknik Elektronika Negeri Surabaya. Surabaya.

[13] Sukmaaji, A., dan Rianto., 2008. Jaringan Komputer Konsep Dasar Pengembangan Jaringan dan Keamanan Jaringan. Edisi Pertama. Andi. Yogyakarta.

[14] Syafrizal, M. 2005. Pengantar Jaringan Komputer. Edisi Pertama. ANDI OFFSET. Yogyakarta.

[15] Suhartono. 2017. Sistem Pengamanan Jaringan Admin Server Dengan Metode Intrusion Detection System (IDS) Snort Menggunakan Sistem Jurnal Mahasiswa IImu Komputer (JMIK) Vol. 01, No. 01, Oktober 2021 Operasi Clearos, 3(1), h. 60-64

[16] Titah, N., Primananda, R., dan 
Akbar, R, S. Perancangan Penempatan Access Point Untuk Jaringan Wifi Pada Kereta Api Penumpang, 2(5), h. 20082010.

[17] Wahyudin, A. 2020. Konfigurasi Mikrotik Untuk Pemula. Edisi Pertama. CV. ATSWA INDONESIA. Surabaya.

[18] Wanda, P. 2020. MENGUASAl JARINGAN KOMPUTER PADA CISCO \& MIKROTIK. Edisi Pertama.CV BUDI UTAMA. Yogyakarta. 